\title{
MERCADO DE TRABALHO E EMPREGABILIDADE SOB A LÓGICA DO CAPITAL: REPRESENTAÇÕES SOCIAIS DO SECRETÁRIO EXECUTIVO NO AMAPÁ
}

\section{LABOR MARKET AND EMPLOYABILITY UNDER THE LOGIC OF CAPITAL: SOCIAL REPRESENTATIONS OF THE EXECUTIVE SECRETARY IN THE STATE OF AMAPÁ, BRAZIL}

\section{Marília Gabriela Silva Lobato}

Mestre em Desenvolvimento Regional pela Universidade Federal do Amapá.

Professora da Universidade Federal do Amapá, Departamento de Filosofia e Ciências Humanas.

E-mail: marilia@unifap.br (Brasil)

\section{Yurgel Pantoja Caldas}

Doutor em Literatura comparada pela Universidade Federal de Minas Gerais - UFMG.

Professor da Universidade Federal do Amapá, Programa de Pós-graduação Mestrado em Desenvolvimento Regional e do Departamento de Letras da UNIFAP.

E-mail: Yurgel@uol.com.br (Brasil)

\section{Arley José Silveira Costa}

Doutor em Ciências pela Universidade de São Paulo - USP.

Professor da Universidade Federal Fluminense, Departamento de Psicologia do Campus de Volta Redonda.

E-mail: arleyunifap@gmail.com (Brasil) 


\title{
MERCADO DE TRABALHO E EMPREGABILIDADE SOB A LÓGICA DO CAPITAL: REPRESENTAÇÕES SOCIAIS DO SECRETÁRIO EXECUTIVO NO AMAPÁ
}

\begin{abstract}
RESUMO
O sistema capitalista, as mudanças no mundo do trabalho e a ideologia da empregabilidade interferem nas representações sobre a condição social e laboral. Assim, este trabalho analisou as representações sociais do Secretário Executivo sobre sua profissão e empregabilidade no mercado de trabalho do Amapá. Quatro bacharéis em Secretariado Executivo empregados, quatro desempregados e quatro acadêmicos de Secretariado Executivo da UNIFAP foram entrevistados. Os discursos foram analisados segundo a teoria das representações sociais. Os secretários caracterizaram seu mercado de trabalho como limitante, com reduzidas remuneração e vagas. A profissão é vista como precarizada, repleta de estigmas negativos e com baixo reconhecimento. Esse quadro é acentuado, embora não produzido, pelas condições econômicas do Amapá que se configuram por reduzido número de empresas, forte presença estatal e políticas públicas voltadas aos grandes projetos que não capilarizam o desenvolvimento. As representações apresentaram a adequação ao mercado flexível e a qualificação permanente como mantenedoras da empregabilidade, evidenciando a influência ideológica e técnica do sistema capitalista. Contraposições individuais ao discurso neoliberal surgem como crítica ao estereótipo da profissão, a precariedade do trabalho e a condição socioeconômica no Amapá que interferem no desenvolvimento da região e na demanda pela força de trabalho do Secretário Executivo. Entretanto, modificar tais representações demanda esforços coletivos, e não apenas individuais, por alterações no contexto da profissão, na forma exploradora como o capital rege o mundo do trabalho e na elaboração de políticas públicas que ampliem o desenvolvimento da região e melhorem a qualidade de vida.
\end{abstract}

Palavras-chave: sistema capitalista; mercado de trabalho; empregabilidade; secretariado executivo; representações sociais. 


\title{
LABOR MARKET AND EMPLOYABILITY UNDER THE LOGIC OF CAPITAL: SOCIAL REPRESENTATIONS OF THE EXECUTIVE SECRETARY IN THE STATE OF AMAPÁ, BRAZIL
}

\begin{abstract}
Capitalist system, changes in the labor market and ideology of employability interfere on representations about social and job conditions. This study analyzed social representations of the Executive Secretary on his profession and employability at the State of Amapa, Brazil. Four bachelors of Executive Secretariat employed, four unemployed and four undergraduated students of Executive Secretariat were interviewed. The speeches were analyzed according to theory of social representations. Secretaries characterized his labor market as a limitation, with reduced salaries and few jobs. Profession of Executive Secretariat is seen as precarious, full of negative stigmas and with low recognition. This picture is enhanced by economic conditions in Amapá, that are configured by few companies, strong state presence, and public policies focused to large projects that do not result in local development. Social representations of secretaries are related to flexible market and qualification as pillars of employability. This highlights the ideological influence of capitalist system over the professionals. Individual confrontations to neoliberal discourse emerge as a critique to the stereotype of the profession, the precariousness of work, and socioeconomic conditions in Amapá. All these factors interfere with the development of the region and the demand by the Executive Secretary workforce. However, the modification of such representations demands collective efforts, not just individual efforts, to change the job context, to modify the way as the capital rules the world of work, and to establish public policies that enhance the development of the region and improve the quality of life.
\end{abstract}

Keywords: capitalist system; labor market; employability; executive secretary; social representations. 


\section{Introdução}

O sistema capitalista difunde, sob as bases de um processo ideológico, diferentes formas de subjugar o trabalhador à reestruturação do capital. A cada indivíduo é atribuída a responsabilidade de qualificação profissional para se adequar à lógica produtivista (Antunes, 2011; Teixeira, 2003). A ideologia da empregabilidade é outro mecanismo para garantir que o trabalhador seja direcionado às perspectivas individualistas de inserção no mercado de trabalho. A adaptação dos indivíduos ao atual modelo flexível tem gerado, exploração, esvaziamento do significado do trabalho e adoecimento. Por isso, faz-se importante entender o sentido que é construído sobre o mercado de trabalho, pela classe que mais se ressente da expropriação que o capital atinge, a dos trabalhadores.

Dentre a classe trabalhadora, Lobato e Aleluia (2011) demonstraram que os secretários executivos se ressentem de sua condição de vida, principalmente laboral, e lutam por equidade. Secretário executivo é uma das poucas profissões em que indivíduos não formados na área, ocupam indiscriminadamente o lugar relativo à profissão. As peculiaridades do mundo de trabalho desta profissão, especialmente em locais como a periferia da periferia do capital, apontam para um mercado restritivo, com intensa precarização da vida laboral, onde a exploração e os processos ideológicos podem estabelecer-se de forma ainda mais forte.

Mesmo com o aumento substancial de vagas no mercado de trabalho brasileiro para a área de secretariado executivo (Nascimento, Maciente, \& Assis, 2013), há discursos recorrentes quanto à insatisfação em relação à atuação do profissional. Lobato e Aleluia (2011) apontaram que a identidade do Secretário Executivo vem sendo construída em um contexto limitante quanto às atribuições assumidas pelos secretários executivos no Amapá. Nesse sentido, é relevante analisar como os trabalhadores veem a si mesmos, suas profissões e as razões responsáveis pelo ingresso e permanência no mercado de trabalho. Assim, esta pesquisa visa compreender os sentidos que profissão, mercado de trabalho e empregabilidade possuem na vida dos secretários executivos.

O sistema de produção interfere em como o indivíduo se percebe em seu meio social e, portanto, foi analisado para discutir os fatores que influenciam na forma de o homem se construir e reconstruir em um meio laboral. As análises levaram em consideração as bases teóricas marxistas de que o trabalho deve configurar como base para a satisfação das necessidades humanas, não somente como um fim para satisfazer o capital. Compreender as representações sociais construídas pelos indivíduos dentro do contexto vivido pode dar subsídios para explicações sobre sua condição social, bem como sobre o comportamento do grupo diante do sistema capitalista e do mercado de 
trabalho. Assim as representações sociais tornam-se um guia para entender parte da realidade (Jodelet, 2001), pois se estruturam nas relações do indivíduo com a sociedade (Madeira, 2014). Representações não são simples concretizações de ideias, mas expressões da realidade social e, assim, devem ser compreendidas a partir do contexto sócio-histórico que as formulam.

Seguindo essa perspectiva, a questão que orienta a execução dessa pesquisa é: quais as representações sociais que o secretário executivo apresenta em relação a seu mercado de trabalho, profissão e empregabilidade no estado do Amapá? Para responder a indagação, procedimentos metodológicos foram adotados com o objetivo de analisar as representações sociais do Secretário Executivo sobre sua profissão e empregabilidade no mercado de trabalho do Amapá.

\section{Referencial teórico}

\section{Compreensões gerais sobre trabalho: determinações que influenciam no mercado de trabalho}

O trabalho está no centro do processo de humanização, pois é a forma originária de toda ação praticada pelo homem, como mecanismo para suprir suas necessidades (Marx, 1996; Lukács, 1974). É condição básica para existência do ser social. Contudo, na sociedade capitalista o trabalho torna-se aviltado e degradado, visto que, em diferentes contextos laborais, o homem deixa de se construir como ser social e passa a se representar como uma peça de autoprodução do capital. Essa questão advém das mudanças no sistema, intensificadas pelo processo de flexibilização do capital, gerando enormes consequências para o mundo do trabalho, como desemprego crescente e precarização das relações trabalhistas (Antunes, 1999). Tais transformações desumanizam a realização do homem pelo trabalho, pois o que deveria ser expressão máxima de transformação do social passa a influenciar o trabalhador a permanecer em um ambiente inibidor, que massacra as possibilidades de alteração na ordem vigente.

As transformações são consequências da crise estrutural do capitalismo que têm origem no excesso da capacidade produtiva industrial e na saturação dos mercados. As baixas taxas de lucros dos anos 1960 evidenciaram o esgotamento do regime fordista, provocando uma transformação estrutural no sistema produtivo para garantir a perpetuação do capital. (Antunes, 2011; Antunes, Pochmann, 2007). A partir dos novos padrões de acumulação, é cada vez mais enfatizada a necessidade do sujeito possuir formação genérica, que lhe possibilite a permanente adaptação ao mundo produtivo. A lógica neoliberal empurra ao processo de qualificação individual a perspectiva de inserção rápida no mercado de trabalho (Teixeira, 2003). Isto transfere ao trabalhador o dever de 
encontrar emprego, mesmo em condições precárias, mas não confronta os índices de desemprego e de precarização do trabalho.

Para que a possibilidade de mudar uma vida precária para outra mais satisfatória não permaneça em segundo plano, é necessário pensar mecanismos que gerenciem mudanças estruturais e conjunturais sobre a apropriação pelo capital das forças de trabalho. O ente que pode formular políticas em benefício da coletividade é o Estado, pois compõe o poder executivo e deve construir estratégias que proporcionem o bem-estar da população (Teixeira, 2003). Nesse contexto, quanto menos desenvolvida for determinada região e apresentar limitações quanto à criação de políticas que gerem mecanismos de subsistência e sobrevivência, mais difícil será a condição da população local e mais necessária a intervenção do Estado por meio de políticas públicas. O Estado não pode se eximir de elaborar políticas que beneficiem os trabalhadores e que envolvam não apenas melhorias na qualificação da população local, mas uma efetiva intervenção na economia que possibilite uma dinâmica produtiva capaz de absorver a força de trabalho e melhorar a condição de vida social.

O papel do Estado é relevante, principalmente, porque no atual cenário capitalista o que se observa não é a criação de políticas de bem comum, mas a implantação de uma lógica neoliberal que garante acesso ao mercado de trabalho à mão de obra que gera mais lucros para o capital. Dessa forma, empregos informais, empregos formais de baixa remuneração, terceirizados e profissões pouco reconhecidas crescem em número, mas permanecem na precarização. Nesse sentido é relevante investigar os sentidos do trabalho e suas representações para a classe que vive do trabalho e que, historicamente, passa por numerosas privações, como ocorre com os Secretários Executivos que lutam pelo reconhecimento no mercado de trabalho amapaense. (Lobato \& aleluia, 2011).

Em uma análise mais específica, imagina-se que o cerne dessa questão, que envolve o mercado de trabalho e a empregabilidade dos Secretários Executivos no Amapá, esteja inclusive, na estrutura do sistema produtivo local. A pesquisa de Chelala (2008) demonstrou a dependência da economia do Amapá em relação à administração pública do estado. Por isso, este trabalho visa compreender a relação que relação estabelecida entre desenvolvimento local, mercado de trabalho e a empregabilidade dos Secretários Executivos.

No anos de 1990, no Amapá, as transferências líquidas financeiras da união representavam cerca de $70 \%$ da receita total do Estado. Esse contexto, sem uma política de transformação da socioeconomia do estado, perpetua a dependência do Amapá em relação à união e demonstra o diminuto recurso próprio do Estado para favorecer o desenvolvimento (Chelala, 2008; Porto, 2003). 
Essa realidade pode ser explicada pela "atratividade reduzida para vinda de novas empresas e sua manutenção no Amapá" (Porto, 2003, pp.177).

Outra questão que fortemente interfere no desenvolvimento do Estado é a participação da administração pública no Produto Interno Bruto do Amapá que é considerada alta e com forte tendência de manter-se estável. O setor público ainda é responsável pelo grande movimento da economia local, concentrando quase a metade do emprego formal da região e apresentando os maiores salários pagos aos trabalhadores (Chelala, 2008).

$\mathrm{O}$ incentivo dos governos Federal e Estadual para dinamizar a exploração mineral e vegetal, na tentativa de garantir o desenvolvimento da região, não foi suficiente para construir mudanças substanciais no Amapá. Porto $(2011,64)$ argumenta que se convencionou denominar o desenvolvimento do Amapá de "capitalismo tardio periférico da periferia", quando comparado com o processo de modernização do Brasil e da Amazônia. O Amapá aparece no cenário nacional como um dos últimos entes federados que iniciou seu processo de industrialização e ainda se encontra deficitário. Porto (2011) relata que o Estado apresenta também uma característica estratégica, mas a partir do olhar do capital internacional, por meio de investimento de grandes empreendimentos do Estado. Santos (2010) enumera alguns projetos que surgiram a partir desse contexto, como a Indústria e Comércio de Minérios (ICOMI), o Complexo Industrial do Jari e a Área de Livre Comércio de Macapá e Santana (ALCMS).

Ao mensurar o interesse internacional na exploração mineral e vegetal do Amapá será dito, sob o discurso do capital, que o Estado apresenta certos picos de desenvolvimento econômico. Porém, é necessário frisar que o retorno social e humano para a população local não foi significativo. Segundo Porto e Costa (1999), a ALCMS não atraiu indústrias que beneficiassem matérias primas da região e restringiu-se à comercialização de produtos importados. $\mathrm{O}$ dinamismo econômico esperado, não ocorreu. Quanto aos Projetos ICOMI e Jari Celulose, os danos ambientais e sociais foram elevados para a região. A figura do governo não serviu para reduzir os impactos negativos que o capital externo desencadeou, nem promoveu o desenvolvimento e qualidade de vida. A prosperidade econômica em benefício da população amapaense continua como promessa. $\mathrm{O}$ reflexo dessa história de exploração foi a permanência do Estado em uma condição ainda periférica, quando comparado aos grandes centros econômicos, inclusive do próprio país. (Chelala, 2008).

A reduzida atratividade de empresas no Amapá e um crescimento econômico atrelado em grande parte à iniciativa pública pode ser inibidor para a contratação de profissionais de secretariado que assessoram os gestores empresariais. Principalmente porque a realidade amapaense 
apresenta um crescimento de empresas privadas ainda pequeno, e muitas com cunho familiar. Em empresas deste tipo há forte concentração das decisões organizacionais, o que pode tencionar em direção a baixos salários para as áreas administrativas, como as dos secretários executivos.

O Amapá apresenta uma quantidade significativa de trabalhadores que se mantém no mercado de trabalho via concurso público, porém as vagas em concursos públicos para secretários executivos são escassas. Observaram-se, neste início de século XXI, concursos abertos para secretários executivos apenas na Universidade Federal do Amapá, Universidade do Estado do Amapá e na Companhia das Docas de Santana.

Mesmo diante de várias questões que podem diminuir as oportunidades de empregabilidade do secretário executivo, há discursos recorrentes de que tornar-se empregável é responsabilidade individual de cada sujeito (Minarelli, 2001; Brunner, 2014). E essa ideia, oriunda do discurso neoliberal de que a classe trabalhadora é responsável por sua entrada e permanência no emprego é uma das formas mais perversas de exploração do sistema capitalista.

A difusão da ideologia da empregabilidade, aparece nos espaços acadêmicos e empresariais, com maior força, a partir dos anos 1990. A empregabilidade é apresentada como a possibilidade de inserção, permanência ou reinserção em quaisquer ambientes de trabalho, principalmente diante de um mundo em constante transformação (Furtado, Lima, \& Bezerra, 2014). A empregabilidade intensifica a ação individual para o sujeito alcançar sucesso, o qual somente seria possível por meio do aperfeiçoamento das qualidades de seus atributos, somado aos conhecimentos a efetividade de suas capacidades pessoais. (Machado, 1998).

Atribuir ao indivíduo seu processo de empregabilidade é uma nova forma de constituir a Teoria do Capital Humano, como estatuto teórico da política educacional implantada da década de 1990 à atualidade. Nessa ótica, o planejamento educacional está voltado às políticas públicas redirecionadas "para atender demandas de uma economia mundializada, sob a égide do projeto societário neoliberal" (Aguiar, 2012, p. 03). Para Oliveira (2005), a Teoria do Capital Humano não considera as relações estabelecidas entre os fatores econômicos, históricos e sociais, mas diz que o homem possui uma racionalidade tal que seria capaz de alcançar seu sucesso econômico. Separa-se, assim, o homem do contexto em que está inserido, e atribuindo-lhe todos os méritos e culpas por sua condição. Frigotto (1998) afirma que a Teoria do Capital Humano julga-se acima de interesses das classes sociais e difunde uma visão de homem e sociedade que se caracteriza por uma apologia ao capitalismo. Ao ignorar as condições estruturais, essa teoria assume uma postura idealista que 
nega a realidade material e passa a ser a expressão de um forte instrumento de apoio ao neoliberalismo.

Por meio da Teoria do Capital Humano, a empregabilidade passa a reproduzir a ideia de que a qualificação para o mercado de trabalho é um pilar para a inserção laboral, e configurando-se em uma manifestação ideológica disseminada pelo discurso do capital. Segundo Antunes (1999, p. 52), "a qualificação e a competência exigidas pelo capital muitas vezes objetivam de fato a confiabilidade que as empresas pretendem obter dos trabalhadores, que devem entregar sua subjetividade à disposição do capital". Dessa forma, no atual sistema capitalista, a luta pela sobrevivência é determinada pelo aumento exponencial da produtividade ao qual a força de trabalho está sujeita, o que não garante bem-estar para grande parte dos trabalhadores, nem a redução do desemprego. (Rodrigues, 2007).

Nesse sentido, as condições materiais da existência humana e as representações se intercalam e precisam ser entendidas no conjunto de seus determinantes. Nesta pesquisa, analisa-se o universo do cotidiano do senso comum compartilhado entre uma classe de trabalhadores, produzido e reproduzido em suas relações socais. Considera-se, para efeito das análises desenvolvidas, que o homem apresenta discursos construídos dentro dessas interações e tais discursos são o meio para dar vazão às representações. E estas podem ser utilizadas como estratégia para construir explicações aproximadas de parte da realidade social de um determinado grupo.

\section{Procedimentos Metodológicos Percorridos}

A pesquisa pautou-se em uma abordagem qualitativa, uma vez que o foco foi a interpretação das representações do grupo investigado. $\mathrm{O}$ método para investigar o objeto foi o histórico dialético, pois se analisou o fenômeno das representações sociais na complexidade dos aspectos que a constituem. Endossando Pires (1997) e Alves (2010), tal método serve como instrumento para a interpretação da realidade.

Para a seleção dos sujeitos participantes da pesquisa, foi realizada identificação dos graduados e graduandos em Secretariado da Universidade Federal do Amapá - UNIFAP, por meio do Departamento de Registro e Controle Acadêmico (DERCA), que ingressaram no período de 1998 a 2011. A seleção dos contatados ocorreu de modo aleatório, na ordem cronológica dos aceites obtidos. Os sujeitos participantes foram selecionados para a entrevista semiestruturada intencionalmente. Devido à profundidade do tema, buscou-se realizar quantas entrevistas fossem 
suficientes para obter o máximo de informações empíricas qualitativas em relação ao objeto de pesquisa. Porém, como a análise foi centrada no discurso do sujeito relacionando-o com sua realidade histórico-social, pensou-se como em Spink (1995, pp. 129) que uma interpretação cuidadosa das subjetividades demanda tempo e cautela nas inferências e, como, consequência, envolvem poucos sujeitos.

A técnica utilizada para compreender as informações empíricas obtidas foi à análise do discurso. Esta permitiu entender as subjetividades, silenciamentos, contradições e a semiótica presente no discurso do grupo investigado. Nesse sentido, utilizou-se Bakhtin (2006) e Orlandi (2013) por considerarem o discurso como mutável, uma forma de expressar a realidade, bem como uma ideia de compreender a construção dos sentidos que são moldados e transformados em uma dada sociedade.

Em seguida, para compreender os fragmentos categorizados, a cada processo discursivo foi retomada a Teoria das Representações Sociais para ancorar as informações obtidas à realidade dos entrevistados. O fragmento do discurso de cada sujeito foi identificado conforme a letra inicial do grupo ao qual pertence, seguido por ordem numérica em que ocorreram as entrevistas, isto é, grupo E, para empregados; grupo D, para desempregados e grupo A, para acadêmicos.

Contextualizar histórica e socialmente as representações identificadas, discutindo teoricamente as variáveis que podem determinar ou não, as representações do grupo pesquisado, só é possível a partir da análise do contexto ideológico de suas formações. Por isso, a pesquisa compreende os aspectos cognitivos com referência às concepções teóricas sobre o mercado do trabalho, a empregabilidade e a profissão de secretário executivo. Estas categorias, por serem centrais para uma mudança em benefício da condição social, podem auxiliar na compreensão dos elementos que afetam o desenvolvimento regional quando se mensura sobrevivência e qualidade de vida.

\section{Análise e Discussão dos Resultados}

As análises deste tópico centraram-se nas representações sociais sobre as três categorias expressas na questão norteadora da pesquisa, profissão, mercado de trabalho e empregabilidade. Essas categorias foram relacionadas ao contexto social, cultural, econômico, político e histórico vivido pelos entrevistados. 


\section{As Representações Sociais do Secretário Executivo: Mercado de Trabalho, Profissão e Empregabilidade}

Para compreender a realidade laboral do Secretário Executivo, é necessário observar o constante desvio de função de tais profissionais, devido à instabilidade econômica, intensificação do processo de terceirização, precarização do trabalho e a própria questão cultural que acompanham historicamente a profissão. Mesmo com o avanço da profissão de secretariado quanto ao número de vagas no mercado de trabalho, há autores (Freitas, 2007; Andrade, Boas, 2009; Lobato, Aleluia, 2011) que apontam uma realidade ainda limitante para a profissão, quanto a estigmas e imaginários sociais que reforçam um contexto que insatisfaz muitos profissionais.

Nesse contexto, há discursos que afirmam que a sociedade macapaense confunde o Secretário Executivo com o profissional de nível médio, afirmando que "quando a gente chega para exercer o secretariado executivo, se depara com uma função que é somente para atender telefone, que não precisa nem ter estudo para executar aquela função”. (Discurso D4).

Outros entrevistados dizem que "para ser secretária aqui, nas empresas privadas [do Amapá], não precisa ter nível superior porque são muito limitadas às funções. Seria atender telefone, fazer anotações. Qualquer pessoa que tem um nível médio pode fazer” (Discurso E1 grifo nosso). Em contexto similar o entrevistado A3 verbaliza que [...] a gente vê empresários que não conhecem a profissão. Não sabem as atividades que a gente exerce.”. (Discurso A3).

O contexto vivido pelo Secretário Executivo influencia a construção de suas representações sociais sobre sua profissão. Como a realidade histórica é elemento que reforça a visão de mundo do Secretário Executivo, pode, também, impactar as representações dos investigados. Dessa forma, como a profissão está envolta de questões que limitam a atuação do Secretário Executivo, as imagens objetivadas reproduzem o reduzido reconhecimento percebido pelos sujeitos que atuam no Amapá. As representações que os Secretários Executivos apresentam em sua profissão estão ancoradas no estereótipo que é reproduzido na sociedade e no imaginário sobre o perfil do emprego de Secretário Executivo.

Existem similaridades no que tange a ação técnica do saber secretarial entre o Bacharel Secretário Executivo e o técnico em secretariado, porém, o conhecimento em relação à assessoria e gerenciamento das demandas organizacionais é fruto de uma formação específica que envolve o ensino superior. Na medida em que é demandada ao Bacharel na área, carreiras que não abrem a possibilidade de exercer sua formação, isto implica em entraves para o exercício profissional. Este contexto reforça a importância da existência de Conselhos Federal e Estadual que pressionem as 
empresas para a contratação de profissionais Secretários Executivos para as vagas que lhes são pertinentes, bem como para ampliar o esclarecimento sobre o exercício da profissão.

Portanto, é necessário considerar o contexto de que se fala para entender a estrutura que influencia no processo de objetivação e ancoragem das representações analisadas. Como cada trabalhador é levado a se adequar ao sistema produtivo local, os Secretários Executivos assim, também o fazem. Como a economia está repleta de empresas de pequeno porte e com ínfimos concursos públicos para a área em questão, tal classe de trabalhadores enfrenta dificuldades de inserção laboral e do exercício da profissão conforme os preceitos legais (Brasil, 1985) em razão dos tipos de empregos disponíveis no Amapá.

Segundo Almeida (2009, p. 44), além de existir o preconceito “ainda persiste o desconhecimento de muitos empresários a respeito da sua capacidade, atribuindo-lhe tarefas simplistas". A centralização das decisões administrativas pelo empresariado local, principalmente em cidades pouco desenvolvidas, indica mais um motivo pelo sentido limitante sobre a realidade do mercado de trabalho para profissionais com nível superior em Secretariado. O profissional apresenta um nicho laboral maior em regiões com sistemas produtivos mais desenvolvidos, como o $\mathrm{ABC}$ paulista (Almeida, 2009), conforme gráfico 1. Nesses territórios, encontram-se um número significativo de empresas que buscam profissionais com formação superior em secretariado para assistir diferentes áreas da administração, uma vez que o processo de descentralização laboral é maior.

Gráfico 1 - Concentração absoluta de Secretário Executivo por UF/ BRASIL (2013)

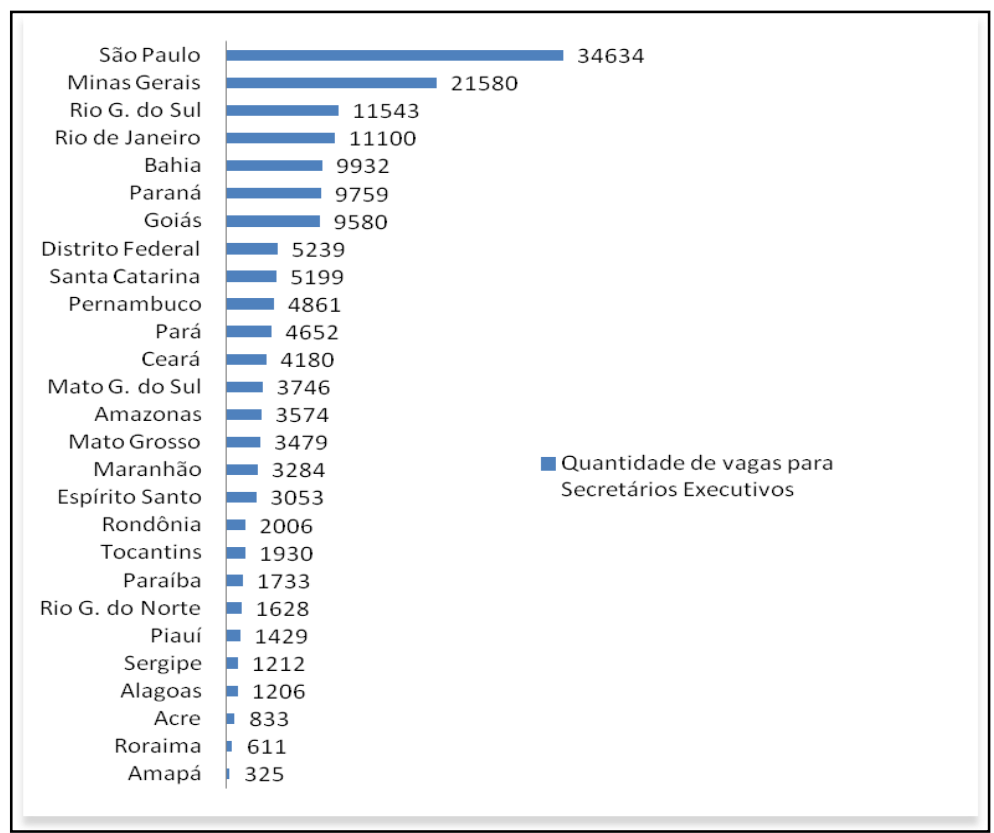

Fonte: Extraído de Lobato (2015). 
Mercado de Trabalho e Empregabilidade Sob a Lógica do Capital: Representações Sociais do Secretário Executivo no Amapá

No último levantamento realizado pelo RAIS (2013) sete unidades da federação (São Paulo, Minas Gerais, Rio Grande do Sul, Rio de Janeiro, Bahia, Paraná e Goiás) concentraram $66,58 \%$ dos postos de trabalho que são ocupados por Secretários Executivos. Somente os Estados de São Paulo e Minas Gerais envolvem mais de um terço das vagas. O Amapá continua com a menor percentagem de vagas registradas formalmente para Secretários Executivos. Na região Norte, o conjunto de ocupações é de $7,37 \%$, ou seja, o valor de toda a região é equivalente a um único Estado do sul do país, o Rio Grande do Sul.

A condição periférica do Amapá, com reduzido desenvolvimento econômico e consequente poucas contratações, reforça a venda de mão de obra abaixo das expectativas dos trabalhadores, tanto em remuneração quanto em reconhecimento e atividades desenvolvidas. A quantidade de empresas de pequeno porte ou microempresas é crescente, mas não se traduz em contratação de mão de obra especializada na área secretarial. A própria economia do local influencia no mercado de trabalho. Em Estados como o Amapá, que possuem retardo em seu crescimento e desenvolvimento devido às políticas que priorizam o caráter exportador da economia local (Porto, 2003), em detrimento do desenvolvimento da região. O cenário é limitante para o mercado de trabalho local principalmente para as profissões, como o Secretário Executivo, que necessitam de uma estrutura empresarial forte para ser absorvidas como mão de obra.

A atividade econômica privada do Amapá tem baixo índice mesmo quando comparada com Estados como Acre, Roraima, Tocantins, Maranhão, Rondônia que não são centrais no capitalismo brasileiro e, ínfima se comparada com São Paulo. O Amapá é o penúltimo estado em quantidade de estabelecimentos totais registrados no RAIS em 2013. A receita de arrecadação de ICMS é tão baixa que a "informação comprova a forte dependência das finanças públicas [...] [do Amapá] em relação às transferências oriundas da União" (CHELALA, 2008, pp. 190).

O problema é que os entes públicos do Amapá também não possuem política clara de contratação do Secretário Executivo. O entrevistado D1 expõe que “o Amapá ainda é o Estado do contra cheque. E a maioria das áreas está na administração pública, se você não conhece alguém, dificilmente é inserido [em vagas no setor público]. [...]" o entrevistado reforça que sabe "de pessoas que entram sem entregar o currículo lá, através de contrato". Isto constrói e reconstrói os sentidos que o emprego pode ter para tal trabalhador, uma vez que os sujeitos são influenciados por sua própria condição de existência. Tanto desempregados, quanto acadêmicos com a formação em secretariado executivo apresentam representações similares quanto a esse ponto. 
Para alguns entrevistados “A maioria dos cargos [de secretário executivo] são indicações e eles não vão verificar se é formado ou não, infelizmente. [...] Aqui na SEED [Secretaria de Educação do Estado do Amapá], por exemplo, ainda vai ter outro concurso para assistente administrativo, mas não entrou secretário executivo" (Discurso E4). Limitações parecidas também foram identificadas no discurso de D4, ao afirmar que "eu fui em uma secretaria [Secretaria estadual] um dia desses e lá eu conheci a secretária do diretor, do diretor dessa instituição pública, ela não tem formação [em secretariado], mas ela é secretária. Então eu vejo que não tem valorização [do Secretário Executivo formado na área]" (Discurso D4).

Ao perpetuar uma política de ocupação de vagas, por indicação, o governo e as prefeituras do Amapá constroem a manutenção de uma cultura que massacra as possibilidades de Secretários Executivos tornarem-se empregáveis nas esferas estaduais e municipais, como apontado no discurso de E1. A figura do Estado deve ser responsável em garantir o surgimento de postos de trabalho, por meio de políticas econômicas focadas no aumento de geração de empregos de qualidade e não somente indicar a contração em virtude de motivação política ou nepotista.

Mesmo com o expressivo aumento no número de vagas para profissionais Secretários Executivos no Amapá, que cresceu de 116 profissionais em 2003 para um total de 325 registrados no RAIS (2013) em 2013, pouco refletiu em mudanças reais no mercado de trabalho para alguns entrevistados. Talvez isso seja reflexo, inclusive das ocupações de vagas para Secretário Executivo por outros indivíduos, que não tenham a formação em nível superior. Nesse contexto, a ausência de um órgão fiscalizador interfere negativamente, inclusive, na expansão efetiva de postos de trabalho para formados na área de Secretário Executivo.

Os sujeitos da pesquisa estão sob o jugo do capitalismo, assim como qualquer trabalhador na sociedade. Isto quer dizer que, dependendo das necessidades do mercado de trabalho local, a força de trabalho requerida será aquela que mais se adequar e submeter ao sistema produtivo. O problema é que reproduzir as demandas do capital, aceitando acriticamente as limitações do mercado de trabalho, pode garantir o emprego e a sobrevivência, mas pode impedir com que o homem torne-se verdadeiramente sujeito ao transformá-lo em mero suporte do capital (Ciampa, 2004). Nesse contexto, um dos entrevistados afirma que:

o setor privado é muito fraco aqui [no Amapá], porque é só comércio e mesmo apesar de todos os incentivos é um comércio fraco. Como a iniciativa privada não é forte e os salários são muitos baixos. As minhas colegas mesmo [fica pensativa] querem pagar muito 
abaixo do piso. $\mathbf{E}$ mesmo concurso de nível médio a pessoa acaba pegando por conta da questão da sobrevivência. (Discurso E1- grifo nosso)

O discurso de E1 pode justificar, em parte, o porquê os profissionais formados em Secretariado Executivo aceitarem desempenhar funções que requeiram apenas a formação em nível médio, no intuito de garantir um meio de subsistência. Nesse sentido, a representação sobre o mercado de trabalho do Secretário Executivo tem influência sobre seu comportamento na busca por emprego. Se o sujeito, mesmo com formação superior não obtém êxito na entrada no mercado de trabalho que pleiteava é comum buscar outras formas de subsistência, abrindo mão do piso salarial e da atuação no nível de ensino em que obteve formação.

Um determinante que afeta diretamente o mercado de trabalho do Amapá é a decisão de investir no desenvolvimento do Estado do Amapá quase que exclusivamente a partir de incentivos fiscais para tornar viáveis empreendimentos privados por intermédio de decretos, como o Distrito industrial de Santana, a ALCMS e a exploração mineral e vegetal dos grandes projetos.

O contexto de desenvolvimento do Amapá se assemelha ao apontado por Boisier (2000). O autor afirma que implantar políticas econômicas que atendam interesses particulares ou de alguns grupos que se beneficiam de seus efeitos, pouco reflete na aplicação de políticas regionais e, consequentemente, na melhoria da condição de vida da população. É preciso, portanto, repensar a forma de investimentos por meio de políticas públicas no Amapá que atualmente, a despeito do volume de recursos envolvidos, não se capilariza em benefício da população.

Diante da realidade socioeconômica citada, das constantes crises e instabilidades econômicas, sem mencionar as desigualdades regionais que inferem na oferta e ocupação de mão de obra, é comum observarmos autores como Mineralli (1995) e Brunner (2001) reforçando apenas o caráter das competências individuais, a empregabilidade, para se alcançar e permanecer no emprego. Entretanto, as competências individuais não são suficientes para explicar o porquê da força de trabalho não se tornar empregável, assim como não resolve o problema para o conjunto dos trabalhadores. A diferença de resultados encontrados neste trabalho e no de Almeida (2009) deixa claro que é preciso considerar as condições econômicas regionais para avaliar e melhorar a qualidade de vida local, não basta atribuir ao capital humano toda a responsabilidade de entrar no mercado de trabalho.

No Estado do Amapá, 67\% dos profissionais registrados no mercado formal de acordo com o RAIS (2013) recebem uma remuneração média de até 3 salários mínimos. Diante da limitação de 
Mercado de Trabalho e Empregabilidade Sob a Lógica do Capital: Representações Sociais do Secretário Executivo no Amapá

oportunidades de emprego formal, os sujeitos da pesquisa assumem cargos abaixo de suas expectativas laborais. $\mathrm{O}$ entrevistado $\mathrm{E} 4$ acredita que:

Eles [a sociedade] não veem a secretária como é vista em outras cidades, que tem multinacionais que tem um mercado de trabalho mais desenvolvido. Eles [a sociedade] não têm ainda essa visão [quebra de fala]. Talvez seja esse reconhecimento que falta da sociedade no mercado de trabalho. (Discurso E4).

Estados como Rio de Janeiro, São Paulo e Distrito Federal apresentam uma faixa mais ampla de Secretários Executivos que recebem salários mais elevados (RAIS, 2013), conforme a tabela 1.

Tabela 1: Faixa Remuneração Salarial Média [em percentagens] de profissionais da área de secretariado Executivo por UF no ano de 2013

\begin{tabular}{|c|c|c|c|c|c|}
\hline UF/BRASIL & $\begin{array}{l}\% \text { de } \\
0,5 \text { a } \\
3,0\end{array}$ & $\begin{array}{l}\text { \% de } 3,0 \\
\text { a } 7,00\end{array}$ & $\begin{array}{c}\% \text { de } \\
7,01 \text { a } \\
+20,00\end{array}$ & $\begin{array}{l}\tilde{\mathbf{n}} \\
\text { class. }\end{array}$ & Total \\
\hline \multicolumn{6}{|c|}{ NORTE } \\
\hline Rondônia & $92,22 \%$ & $5,18 \%$ & $2,09 \%$ & 10 & 2006 \\
\hline Acre & $79,95 \%$ & $18,00 \%$ & $1,56 \%$ & 4 & 833 \\
\hline Amazonas & $46,97 \%$ & $38,27 \%$ & $14,71 \%$ & 1 & 3574 \\
\hline Roraima & $69,39 \%$ & $22,25 \%$ & $8,34 \%$ & 0 & 611 \\
\hline Pará & $78,24 \%$ & $16,98 \%$ & $4,57 \%$ & 9 & 4652 \\
\hline Amapá & $67,38 \%$ & $19,38 \%$ & $13,23 \%$ & 0 & 325 \\
\hline Tocantins & $84,92 \%$ & $11,60 \%$ & $3,47 \%$ & 0 & 1930 \\
\hline \multicolumn{6}{|c|}{ NORDESTE } \\
\hline Maranhão & $79,68 \%$ & $14,43 \%$ & $5,66 \%$ & 7 & 3284 \\
\hline Piauí & $87,61 \%$ & $8,95 \%$ & $3,35 \%$ & 1 & 1429 \\
\hline Ceará & $78,80 \%$ & $15,14 \%$ & $5,78 \%$ & 11 & 4180 \\
\hline Rio G. do Norte & $80,28 \%$ & $12,46 \%$ & $6,81 \%$ & 7 & 1628 \\
\hline Paraíba & $81,65 \%$ & $13,09 \%$ & $5,40 \%$ & 3 & 1733 \\
\hline Pernambuco & $75,39 \%$ & $16,68 \%$ & $6,99 \%$ & 45 & 4861 \\
\hline Alagoas & $78,52 \%$ & $13,34 \%$ & $7,62 \%$ & 6 & 1206 \\
\hline Sergipe & $79,53 \%$ & $13,94 \%$ & $5,94 \%$ & 7 & 1212 \\
\hline Bahia & $62,26 \%$ & $18,32 \%$ & $19,10 \%$ & 30 & 9932 \\
\hline \multicolumn{6}{|c|}{ SUDESTE } \\
\hline Minas Gerais & $82,14 \%$ & $13,18 \%$ & $4,06 \%$ & 131 & 21580 \\
\hline Espírito Santo & $65,47 \%$ & $25,31 \%$ & $8,94 \%$ & 8 & 3053 \\
\hline Rio de Janeiro & $49,30 \%$ & $26,82 \%$ & $22,88 \%$ & 109 & 11100 \\
\hline São Paulo & $47,40 \%$ & $27,83 \%$ & $24,13 \%$ & 218 & 34634 \\
\hline \multicolumn{6}{|c|}{ SUL } \\
\hline Paraná & $63,38 \%$ & $27,68 \%$ & $8,37 \%$ & 54 & 9759 \\
\hline Santa Catarina & $75,97 \%$ & $17,33 \%$ & $5,46 \%$ & 64 & 5199 \\
\hline Rio Grande do Sul & $68,40 \%$ & $20,38 \%$ & $9,78 \%$ & 165 & 11543 \\
\hline \multicolumn{6}{|c|}{ CENTRO-OESTE } \\
\hline Mato Grosso do Sul & $82,59 \%$ & $9,82 \%$ & $7,07 \%$ & 19 & 3746 \\
\hline Mato Grosso & $87,41 \%$ & $8,42 \%$ & $3,85 \%$ & 11 & 3479 \\
\hline Goiás & $86,78 \%$ & $9,69 \%$ & $3,19 \%$ & 31 & 9580 \\
\hline Distrito Federal & $47,10 \%$ & $26,01 \%$ & $26,41 \%$ & 24 & 5239 \\
\hline Total & & & & 975 & 162308 \\
\hline
\end{tabular}

Fonte: Adaptado de Lobato (2015). 
Essa informação da relação entre desenvolvimento econômico da região e remuneração profissional perpassa as representações sociais dos secretários do Amapá. Nessa linha, o discurso de E1 afirma que "em outros estados a profissão é mais reconhecida, porque dependendo da economia [o profissional] é necessário. Por exemplo, em São Paulo, Centro-Sul, geralmente o salário é melhor e a pessoa tem que ser mais especializada". A concepção de E1 é percebida quando se analisa a tabela 1, uma vez que as maiores percentagens de trabalhadores que recebem entre sete e vinte salários mínimos estão nos estados de São Paulo, Rio de Janeiro e Distrito Federal.

Entre os Estados da região Norte, há, também, ampla disparidade de remuneração. Um fator que pode explicar a diferença entre os valores recebidos pelos Secretários Executivos pode ser o volume de profissionais inseridos na administração pública, uma vez que esta, ainda, representa os maiores salários em relação aos demais setores econômicos. No estado do Amazonas, por exemplo, cerca de 38,27\% desses profissionais recebem de três a sete salários mínimos e 14, 71\% recebem de sete até mais de 20 salários mínimos.

O fato de constatarmos pisos salariais diferentes em cada estado da Federação pode indicar mais um entrave advindo da inexistência de um Conselho que fiscalize o exercício profissional. Essa questão se traduz em precariedade laboral durante o exercício profissional do Secretário Executivo, devido os reduzidos salários que são pagos a vários profissionais. Para citar alguns exemplos, 81,9 \% dos Secretários Executivos de Rondônia registrados no RAIS, em 2013, recebem até dois salários mínimos. No Pará, essa percentagem chega a 64,5\% e, no Amapá, a 46,7\% dos profissionais. Para indivíduos com formação superior, como é o caso do bacharel em Secretariado Executivo, o retorno salarial na magnitude atual é inadequado e insuficiente. Essa compreensão é sumarizada na fala de um dos entrevistados ao afirmar que "o salário não compensa a graduação de quatro anos". (Discurso A1).

Enquanto o Conselho Federal de Secretariado não é institucionalizado, a classe dos trabalhadores em secretariado executivo continua, por meio da Federação Nacional de Secretárias e Secretários (FENASSEC), pleiteando junto ao Ministério do Trabalho, a possibilidade de abrir o projeto de lei engavetado, para que, futuramente, o Conselho Federal de Secretariado seja regulamentado. A existência da entidade nas esferas federal e estadual poderia reduzir as distorções quanto aos salários recebidos pela categoria, assim como, diminuir o exercício ilegal da profissão.

Mesmo em um ambiente limitante, com uma economia baseada na administração pública, mas com reduzido número de cargos públicos para o Secretário Executivo, o trabalho continua central na vida dos entrevistados. Porém, para expandir as liberdades individuais, a saída está na 
busca por empregos em diferentes áreas que atendam as necessidades de melhoria de faixa salarial ou mesmo somente para garantir subsistência, na ausência de emprego na área pleiteada. Acatar essa configuração tem efeito sobre as representações sobre a forma como os secretários visualizam o trabalho que desempenham. Os fragmentos abaixo exemplificam as principais definições sobre a categoria "mercado de trabalho" representada pelos entrevistados. E3 afirma que o trabalho desagrada

porque não trabalhamos oito horas como está na lei, às vezes passamos 10, 11 horas na empresa, tem reuniões a noite que você fica a disposição. E isso tudo não há um retorno em gratificação e sim fica em um banco de horas e você pode usar aquelas horas que estão excedendo. A empresa deixa claro isso e o colaborador não tem muito que reclamar. Porque na hora que ele é contratado a empresa deixa bem claro que pode ter dias que você [o trabalhador] sairá mais tarde. Você aceita o emprego já sabendo disso. Já sendo consciente disso (Discurso E3).

O profissional, embora não goste das condições vigentes no exercício laboral, submete-se a ele como estratégia para entrar e manter-se no mercado de trabalho. É necessário, portanto, combater a lógica neoliberal que transforma os sentidos do trabalho, em apenas um sustentáculo da acumulação do capital que priva o homem de expandir suas liberdades individuais (Sen, 2000). A entrevistada finaliza afirmando que isso é realidade recorrente em empresas privadas do ramo da construção civil no Amapá. Sabino (2006) reitera que estas questões são comuns em todo Brasil. A autora aplicou 790 questionários no ano de 2006 a profissionais de secretariado em diferentes regiões do país e constatou que $62 \%$ das repostas indicaram a permanência no local de trabalho, além das oito horas previstas em lei com o intuito de atender as necessidades da empresa. É provável que seja dessa condição que a Classificação Brasileira de Ocupações (2010, pp. 355) se refira ao afirmar que o profissional Secretário Executivo pode "permanecer em posições desconfortáveis por longos períodos". Tal afirmação constar na descrição da profissão é, no mínimo, a institucionalização da exploração contra a qual os trabalhadores historicamente vêm lutando e que compõe o perfil da sociedade capitalista.

O Secretário Executivo, para manter-se no emprego, suporta conscientemente a exploração de sua mais valia devido às dificuldades em promover alternativas de modificação. Mas na medida em que o trabalho é a garantia de sobrevivência, a precariedade das relações trabalhistas acaba colocada em segundo plano no rol das ações humanas e suportada, apesar de todos os malefícios 
que gera. Para Antunes (2011) mencionando Marx a sociedade capitalista é tão perversa que faz do trabalho um meio para reproduzir o capital e não a primeira necessidade humana.

Quando indagados sobre os mecanismos de transformação atual para tornarem-se empregáveis no mercado de trabalho para Secretário Executivo, o entrevistado A1 verbalizou que “A ascensão profissional depende do esforço de cada profissional” (Discurso A1- grifo nosso) para permanecer no mercado de trabalho. O Discurso de E2 demonstra a mesma percepção quando relata: "Eu creio que cada vez mais [é necessário] buscar conhecimento, buscar se especializar" (Discurso E2 - grifo nosso) para obter emprego. A perspectiva de conseguir melhores condições laborais continua sendo caracterizada a partir do processo de qualificação, como exposto por E4, dizendo que: Eu acho que ele precisa estar se aperfeiçoando cada vez mais, ter formações paralelas que possam dar a eles [os Secretários Executivos] um alicerce maior na vida profissional dele. Não focar só na parte de secretariado [...] (Discurso E4).

A categoria empregabilidade é representada pelos entrevistados a partir da imagem de esforço individual e de aperfeiçoamento profissional, percebidos como os principais mecanismos de mudança laboral. Essas imagens objetivadas estão ancoradas na busca por alternativas de emprego e ascensão profissional. As representações construídas sobre a empregabilidade também influenciam na prática social do Secretário Executivo e vice-versa. Tais representações refletem a ideologia da empregabilidade, nas quais é responsabilidade de cada indivíduo obter emprego. Mesmo diante de diferentes determinações apontadas pelos entrevistados como limitantes para o exercício profissional, a formação e qualificação profissional aparecem como a saída mais prática e imediata. Esta perspectiva, apesar de, no máximo, resolver casos individuais, é corroborada por Bortolotto e Rinaldi (2008, pp. 8) como se o processo de qualificação profissional, por si só, fosse suficiente para resolver os problemas históricos que a profissão enfrenta. Os autores afirmam que os profissionais que desejam atuar na área de secretariado executivo precisam "se conscientizar que a qualificação profissional é o melhor caminho para conquistar o reconhecimento profissional, superar os tabus impostos a profissão, e assim construir uma identidade".

É cada vez mais comum que as representações sobre empregabilidade norteiem o comportamento dos Secretários Executivos em direção à obtenção de emprego baseado somente nos atributos individuais, visão reforçada pela teoria do capital humano. Contudo, a qualificação educacional não é solução para o problema global do desemprego do conjunto dos trabalhadores da área de secretariado. A solução individual via empregabilidade não modifica a estrutura em que as dificuldades de inserção no mercado de trabalho estão sustentadas, como os entraves sociais, 
econômicos, educacionais, culturais e os estigmas que a profissão enfrenta. Ao considerar o sentido do conteúdo das representações emitidas compreende-se que o discurso neoliberal influencia na forma como os Secretários Executivos representam sua empregabilidade.

Mesmo que outros discursos tenham demonstrado as dificuldades econômicas, políticas e culturais para inserção do indivíduo formado em Secretariado Executivo no mercado de trabalho do Amapá, as respostas aos problemas vivenciados envolveram basicamente a empregabilidade por meio do processo de qualificação profissional. Mas isto, por si só, não amplia o número de empregos disponíveis aos Secretários Executivos, não modifica o processo de indicação política na contratação de Secretários Executivos para a ocupação da profissão, e tampouco, modifica o imaginário social da sociedade quanto aos estereótipos difundidos sobre a área ou implanta uma média salarial menos precarizada para o profissional.

A qualificação profissional, embora relevante para que o sujeito construa alternativas de sobrevivência, pouco contribui para transformação da realidade dos trabalhadores envolvidos no processo. Uma hipótese possível à questão de atribuir ao indivíduo a responsabilidade por sua empregabilidade vincula-se ao próprio processo de formação do Secretário Executivo. A necessidade de adequação às exigências mercadológicas são maiores do que a construção de uma análise crítica sobre os problemas sociais, como a questão de desemprego ou trabalho precário. Por isso, há a necessidade de considerar o sistema capitalista explorador e as condições de reduzido desenvolvimento para compreender as contradições sobre emprego e desemprego.

Este trabalho é exatamente uma das possíveis tentativas de compreensão dos fatores que interferem sobre o mercado de trabalho e a empregabilidade do Secretário Executivo. É correto afirmar que investigações sobre essa temática e sobre o modelo de educação voltado para o curso de secretariado executivo no Brasil devem ocorrer em pesquisas futuras, pois parece ser um item preponderante para compreender as representações construídas desde a graduação até a entrada no mercado de trabalho dos sujeitos da profissão.

É importante, também, para compreender a aparente ausência de um posicionamento mais crítico com relação às condições de exploração implantadas no mundo do trabalho aos quais os secretários executivos, assim como os demais profissionais, estão sujeitos. Brandão (2010, pp. 184) explana que a "formação tem sido mais orientada para atender ao mercado de trabalho, o que não favorece a construção de um profissional com autonomia, no sentido de ser tomador de decisões complexas, relacionadas às estratégias das organizações". Para modificar esse contexto, é 
"necessário romper com a lógica do capital se quisermos contemplar a criação de uma alternativa educacional significativamente diferente” (Mészáros, 2008, pp. 27).

Os resultados encontrados e os posicionamentos desses autores caracterizam-se como elementos significativos para que novas pesquisas sejam desenvolvidas sobre a estrutura de formação e o tipo de representação com relação a inserção no mercado de trabalho que os bacharelados em Secretariado Executivo estão implantando.

Além disso, é possível imaginar ações que, tendo por base a classe que vive do trabalho, possam incentivar um processo que "dê início a uma organização societária emancipada, fundada em valores para além do capital, do mercado, do lucro, que possibilitem a existência de seres sociais omnilaterais, 'livremente associados"” (Antunes, 2011, pp. 165). Permanecer refém do atual sistema explorador, alheio aos problemas sociais, não constrói mecanismos de mudança social, apenas reproduz a lógica do capital que aliena o trabalhador reduzindo-o a condição de coisa, como está sendo o caso para o Secretário Executivo, pelo menos em locais como o Amapá que se encontram na periferia da periferia do capital.

\section{Considerações Finais}

O trabalho, como princípio formador do ser social, continua sendo central na vida das pessoas por ser a base da sobrevivência e da satisfação das necessidades sociais do homem. Porém, as transformações no sistema capitalista para garantir a continuidade de sua reprodução, constroem mudanças significativas no mundo, mas principalmente para a classe que vive do trabalho. $\mathrm{O}$ trabalho deixa de responder as demandas dos trabalhadores para satisfazer a lógica neoliberal, principalmente quando se analisa categorias como mercado de trabalho, profissão e empregabilidade. O trabalhador é levado a se adequar aos padrões flexíveis do mercado, ao sistema produtivo local e às ideologias criadas para aumentar o processo de exploração do homem.

Nesse estudo foi possível observar que os indivíduos que representaram a classe trabalhadora investigada, os secretários executivos, estão sujeitos a uma lógica de exploração que é própria do capital, mas que pode refletir nuanças dos determinantes a que estão submetidos. Nesse sentido, a realidade do Amapá difere da encontrada nos grandes centros, principalmente por se encontrar em um território periférico, com uma dinâmica econômica menos desenvolvida e uma economia atrelada aos recursos públicos, o que influencia no perfil da força de trabalho local. Esse 
contexto determinou a forma como os sujeitos representaram as três categorias analisadas, mercado de trabalho, sua profissão e a noção de empregabilidade.

O mercado de trabalho foi definido como limitante, aspecto que influenciou na representação dos entrevistados sobre mercado de trabalho. Esse contexto pode ser melhor compreendido quando são analisadas as bases que ancoraram as representações. Alguns elementos explicativos estão relacionados à condição socioeconômica do Estado que reduz as possibilidades de encontrar emprego em um ambiente com pouco incentivo à implantação de grandes empresas. Fato que se modificado poderia auxiliar na contratação de profissionais não-liberais, como os Secretários Executivos.

Quanto à profissão, além de influências da condição local, apresentou determinações históricas, em relação ao imaginário social construído sobre a identidade dos profissionais da área. Isto caracterizou a profissão como estigmatizada e pouca reconhecida, o que pode ter influenciado nas representações que os sujeitos construíram sobre sua vida laboral. Por isso a necessidade de intervenção do estado para criar políticas públicas de emprego que melhorem a qualidade de vida dos secretários executivos, assim como de toda população. E não simplesmente criar políticas pontuais para o benefício de alguns poucos. Esta condição pode desenvolver o mercado de trabalho e modificar as representações dos SE sobre sua profissão.

A categoria empregabilidade apresentou objetivações que se assemelharam a perspectiva da Teoria do Capital Humano, pois os entrevistados mencionaram formação constante, especializações e busca por conhecimento para mudar sua vida profissional. Os discursos evidenciaram que as representações dos secretários executivos sobre sua profissão e empregabilidade refletem a ideologia da competência pessoal e qualificação como requisitos principais para a entrada e permanência no mercado de trabalho. É possível modificar tais representações, desde que o atual contexto limitante também seja modificado. Para isso, seria necessário alterar o próprio sistema capitalista alterado, pois assim seria possível construir um processo de reinvenção da sociedade, com a noção de trabalho mais humanizado e menos precarizado. Sob uma ótica marxista dialética, essa mudança somente ocorreria a partir de um mecanismo revolucionário de luta que deveria envolver toda a classe que vive do trabalho e não apenas grupos fragmentados.

Se, em curto prazo não é possível promover alterações significativas na construção de um mundo mais satisfatório para os Secretários Executivos, é preciso construir outras estratégias, mesmo que dentro da lógica instituída. Inicialmente, com a continuidade das lutas sociais para 
construir um projeto de lei que crie o Conselho Federal de Secretariado e garanta a físcalização do exercício legal da profissão. Além disso, a União e o Estado do Amapá precisam estabelecer políticas públicas de emprego que beneficiem a população local, facilitem a expansão das liberdades individuais e aumentem o trabalho formal tanto na esfera pública como privada. $\mathrm{O}$ estado, embora não seja a solução total para o problema, é figura relevante para a criação de políticas de emprego que assistam as mais diferentes classes que vivem do trabalho, pois pode intervir na contínua exploração do homem pelo sistema vigente que é fator chave para a manutenção da realidade precária a que os trabalhadores estão submetidos.

Não se busca, neste trabalho, esgotar as definições e explicações sobre as representações sociais estudadas, mas iniciar a compreensão de sua gênese. É necessário que outras investigações sejam realizadas para compreender o processo que influencia na construção dessas representações, desde a formação profissional dos secretários executivos, a imagem destes no mercado e a empregabilidade entre outros temas.Conforme identificado nesse estudo, realidades distintas geram representações sociais diferentes e, portanto, estudos que abranjam os diferentes contextos, aos quais os profissionais de secretariado estão expostos, são relevantes para compreender a complexidade e as idiossincrasias que permeiam a profissão. Essas pesquisas poderiam construir explicações aproximadas sobre a falta de concursos públicos na área de secretariado executivo, incluindo análises do discurso dos gestores públicos.

O profissional de Secretariado Executivo tem mostrado sua competência e relevância para as organizações nas quais se insere, embora o ambiente laboral, especialmente em localidades na periferia do capital, como é o caso do Amapá, ainda não o acolha com o devido respeito e remuneração. Entretanto, sendo uma das profissões que mais cresceram no país, as perspectivas para o exercício laboral são favoráveis. A existência dos conselhos profissionais, de sindicatos atuantes em defesa da categoria e de cursos voltados para uma formação omnilateral serão mecanismos importantes para alavancar ainda mais o crescimento da profissão e seu reconhecimento.

\section{REFERÊNCIAS}

Aguiar, L. C. (2012). Teoria do capital humano nas políticas públicas para a educação brasileira e catarinense. Atos de pesquisa em educação, vol. 7, n. 1, pp. 2-26, jan./abr.

Almeida, R. de. (2009). A construção da identidade do ser profissional secretário na Região do Grande ABC. 206f. Dissertação de Mestrado, Universidade Metodista de São Paulo. Faculdade de Administração e Economia. São Bernardo do Campo. 
Alves, M. A. (2010). O método materialista histórico-dialético: alguns apontamentos sobre a subjetividade. Revista de Psicologia da UNESP, vol. 9, n. 1, pp. 1-13.

Andrade, E. C. de \& Boas, M. C. V. (2009). Qual a themata do secretário executivo explorada pelo cinema à luz das representações sociais. Revista Intersaberes, Curitiba, ano 4, n. 7, pp.89-107, jan./jun.

Antunes, R. (1999). O mundo precarizado do trabalho e seus significados. Cadernos de Psicologia Social do Trabalho, vol. 2, n. 1, pp. 55-72.

Antunes, R. (2011)Adeus ao trabalho? Ensaio sobre as metamorfoses e centralidade do mundo do trabalho. 7. ed. São Paulo: Cortez.

Antunes, R. \& Pochmann. M. (2007). A desconstrução do trabalho e a explosão do desemprego estrutural e da pobreza no Brasil.

Bakhtin, M. (2006). Marxismo e filosofia da linguagem. 12. ed. São Paulo: Hucitec.

Boisier, S. (2000). Desarrollo Local: de qué estamos hablando? . In: Becker, D. F; Bandeira, P. S. (Org.). Desenvolvimento local/regional: determinantes e desafios contemporâneos. Santa Cruz do Sul: EDUNISC, v. 1, pp. 151-185.

Bortolotto, R. M. \& Rinald, R. N. (2008). O ensino superior de Secretariado Executivo na região Sul do Brasil. Expectativa: revista do Curso de Secretariado Executivo, Toledo: Universidade Estadual do Oeste do Paraná - Campus de Toledo Gráfica Universitária, v. 7, n. 7, pp. 9-25.

Brasil (1996). Lei n. 7.377, 30 de setembro de 1985. Brasília. Recuperado em 22 jun 2013 de <http://www.planalto.gov.br/ccivil_03/leis/L9261.htm>.

Brasil. Ministério do Trabalho e Emprego. Classificação Brasileira de Ocupações (CBO): Código, título e descrições. Brasília, DF, 2010.

Brandão, M. N. (2010). Formação do profissional secretário executivo na UFC: currículo, competência e cidadania. 225f. Tese de Doutorado em educação, Universidade Federal do Ceará, Faculdade de Educação, Ceará.

Brunner, J. competencias de empleabilidad. (2014).Recuperado em 20 ago. 2014 de <http://www. geocities.com/brunner_cl/ empleab.htlm>.

Chelala, C. A. (2008). A magnitude do Estado na socioeconomia amapaense. Macapá: UNIFAP.

Ciampa, A. Identidade. (2004). In: Lane, S. T. \& M.; Codo, W. (Org.). Psicologia social: o homem em movimento. São Paulo: Brasiliense.

Freitas, K. (2007) O lugar da secretária: implicações históricas de gênero no trabalho e imagem da profissão. In: ENCONTRO E GESTÃO DE PESSOAS E RELAÇÕES DE TRABALHO, 1., 2007, Natal. Anais... Natal, 2007. 
Frigotto, G. (1998). Educação e crise do trabalho: perspectivas de final de século. Petrópolis: Vozes.

Furtado, E. D. P., Lima, K. R. R.\& Bezerra, J. E. B. (2014). Competência e empregabilidade: a novilíngua neoliberal. Recuperado em 2 ago. 2014 de $<$ http://www.estudosdotrabalho.org/anais6seminariodotrabalho/elianefurtadokatialimaejoseeudesbe zerra.pdf $>$.

Jodelet, D. (2001). As representações sociais: um domínio em expansão. In: Jodelet, D. (Org.). As representações sociais. Rio de Janeiro: EdUERJ. pp. 17-44.

Lobato, M. G. S. \& Aleluia, M. da S. O bacharel em Secretariado Executivo: uma análise pelo conceito de identidade-metamorfose. 2011. $51 \mathrm{f}$. Trabalho de Conclusão de Curso de, Secretariado Executivo, Universidade Federal do Amapá, Macapá, 2011.

Lobato, M. G. S. (2015). Mercado de trabalho e empregabilidade sob a lógica do capital: Representações Sociais do Secretário Executivo no Amapá (1998-2011). Dissertação de Mestrado, Mestrado em Desenvolvimento Regional, Universidade Federal do Amapá, Macapá.

Lukács, G. (1974). História e consciência de classe. Tradução Telma Costa. Lisboa: Publicações Escorpião.

Machado, L. R. de S. (1998). Educação Básica, empregabilidade e competência. Revista trabalho e educação, Belo Horizonte, n. 3, jan./jul..

Madeira, M. C. (2014). Representações sociais de professores sobre a própria profissão: à busca de sentidos. Universidade Católica de Petrópolis (UCP). Recuperado em 22 jan 2014 de <http://23reuniao.anped.org.br/textos/2027t.PDF>.

Marx, K. (1996). O capital: crítica da economia política; o processo de produção do capital. Tradução Regis Barbosa e Flávio R. Kothe. São Paulo: Nova Cultural. Livro primeiro, Tomo 1, v. 1 .

Mészáros, I. (2008). A educação para além do capital. Tradução Isa Tavares. São Paulo: Boitempo.

Minarelli, J. A. (2001). Empregabilidade: como ter trabalho e remuneração sempre. São Paulo: Gente.

Nascimento, P. A. M. M., Maciente, A. N.\& Assis, L. R. S. de. (2013). As ocupações de nível superior que mais geraram empregos entre 2009 e 2012. Resumo técnico. Radar: tecnologia, produção e comércio exterior 2009-2012, n. 1. Brasília: Instituto de Pesquisa Econômica Aplicada (IPEA).

Oliveira, A. de. (2005). Planejamento urbano e geração de empregos: a cidade de São Paulo (Brasil) nos anos 90. Revista Eure, Santiago de Chile. vol. 31, n. 92, pm.47-64, maio. 

Pontes.

Orlandi, E. P. (2013). Análise do discurso: princípios e procedimentos. 11. ed. Campinas:

Pires, M. F. de C. (1997). O materialismo histórico-dialético e a educação. Interface Comunicação Saúde, Educação, pp. 83-94, ago.

Porto, J.L.R. (2003). Amapá: principais transformações econômicas e institucionais (19432000). Macapá: SETEC.

Porto, J.L.R. (2011). Reflexões sobre a condição periférica-estratégica da fronteira amapaense. Para Onde!? Revista eletrônica do Programa de Pós-Graduação em Geografia, Universidade Federal do Rio Grande do Sul, Porto Alegre, vol. 5, n.2, pp. 63-75, ago./dez.

Porto, J.L.R. \& Costa, M. (1999). A Área de Livre Comércio de Macapá e Santana: questões geoeconômicas. Macapá: O Dia.

Relação Anual De Informações Sociais (RAIS). (2013). Recuperado em 5 jan 2015 de

< bi.mte.gov.br/bgcaged/caged_rais_vinculo_id/caged_rais_vinculo_basico_tab.php>.

Rodrigues, D. (2007). A mercadoria da força de trabalho com parte fundante da reprodução do capital. Universidade e Sociedade, Brasília, DF, ano 17, n. 40, jul. 2007.

Sabino, R. F. (2006). A profissão de secretário executivo no Brasil: políticas para formação e emprego. 213 f. Dissertação de Mestrado em Educação, Administração e Comunicação, Universidade São Marcos, São Paulo

Santos. E. R. (2010). Grandes projetos amazônicos e configuração geográfica do Amapá. In: Interações fronteiriças no Platô das Guianas: novas construções, novas territorialidades. pp. 45-72, Macapá: Publit.

Sen, A. (2000). Desenvolvimento como liberdade. Tradução Laura Teixeira Motta. São Paulo: Companhias das Letras.

Spink, M. J. (1995) Desvendo as teorias implícitas: uma metodologia de análise das representações. In:. Guareschi, P. A., Jovchelovitch, S. (Org.). Textos em representações sociais. 2. ed. Petrópolis: Vozes.

Teixeira, R. C. F. (2003). A passagem do direito ao trabalho para a empregabilidade: privatização do espaço público através das políticas sociais de emprego na contemporaneidade. UNIMONTES Científica, ano 1, v.5. Recuperado em 15 jan 2015 de

<http://www.ruc.unimontes.br/index.php/unicientifica/article/viewArticle/80>. 